Published in: Agronomy Journal, 2008, Vol. 100, No. 5, pgs. 1242-1247

\title{
A Wheat Grazing Model for Simulating Grain and Beef Production: Part I- Model Development
}

\author{
X-C Zhang ${ }^{1 *}$, W.A. Phillips, J.D. Garbrecht, J.L. Steiner, L.A. Hunt
}

\begin{abstract}
It is a common practice to grow winter wheat (Triticum aestivum L.) as a dual-purpose crop in the U.S. Southern Great Plains to decrease production risk and to increase profit margin through cattle (Bos taurus) production. Crop management of the dual-purpose wheat is complex because of the tradeoffs between beef production and wheat grain yield. A wheat grazing model helps in making optimal decision. The objective of this study was to develop and incorporate a grazing and metabolizable energy-based cattle growth module into the Decision Support Systems for Agrotechnology Transfer (DSSAT) to simulate beef and wheat grain production. The wheat grazing model was comprised of wheat growth, wheat-cattle interaction, and cattle growth components. Wheat growth was simulated by the cropping system model (CSM) of DSSAT. For the wheat-cattle interface, removals of canopy biomass and leaf area by grazing were estimated daily. Predicted grain yield was also reduced by $50 \mathrm{~kg} \mathrm{ha}^{-1}$ per day for each day of grazing past the first hollow stem stage. Cattle growth rate was based on a metabolizable energy intake. Maximum voluntary daily intake was estimated based on stocker body weight and forage quality, and is further adjusted for actual forage availability, temperature, and adaptation status during the first two week of grazing to estimate the actual daily intake. Changes in wheat growth processes brought about by grazing, including a grazing effect on the delay of plant phenological development, are not simulated in the model. Field experiments to characterize any such effects are needed to help fine-tune the model.
\end{abstract}

\footnotetext{
${ }^{1}$ X-C Zhang, W.A. Phillips, J.D. Garbrecht, and J.L. Steiner, USDA-ARS Grazinglands Research Laboratory, 7207 W. Cheyenne St., El Reno, OK 73036; L.A. Hunt, Dep. of Plant Agric., Univ. of Guelph, Guelph, Ontario, Canada N1G 2W1 (retired). * Corresponding author (John.Zhang@ars.usda.gov).
} 
Abbreviations:

BW: body weight

CSM: cropping system model

DM: dry matter

DSSAT: decision support systems for agrotechnology transfer

ET: evapotranspiration

FHS: first hallow stem

LAI: $\quad$ leaf area index 


\section{INTRODUCTION}

It is a common practice to grow winter wheat as a dual-purpose crop for grain and cattle production in the US Southern Great Plains, which includes the Texas Panhandle, western Oklahoma, southwestern Kansas, southeastern Colorado, and eastern New Mexico. Similar dual-purpose production systems are found in parts of South America and Australia. Millions of hectares of hard red winter wheat in the US Southern Great Plains are grazed between late fall and early spring to convert high quality biomass into body weight gain and to reduce economic risk to the total enterprise. In Oklahoma, more than 2.4 million hectares of wheat were seeded in 2000 and nearly one million hectares were grazed by cattle based on a survey by Hossain et al. (2004). Winter wheat in dual-purpose systems is normally planted approximately one month earlier than grain-only wheat, and is typically grazed from mid-November to early March at an average stocking rate of one steer per ha (Phillips and Albers, 1999). Assuming an average daily gain of $1 \mathrm{~kg}$ and a market value of $\$ 2$ per $\mathrm{kg}$ of live animal weight, grazing winter wheat in Oklahoma is a 2-million-dollar per day enterprise. Redmon et al. (1995) reported that the averaged annual net returns to the wheat grain-cattle enterprise in Oklahoma from 1984 to 1993

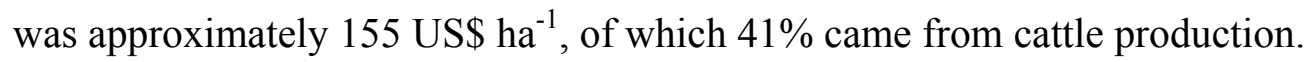

Management of dual-purpose wheat production is complex, because of multifaceted interactions and tradeoffs between cattle and wheat grain production, which are further complicated by the effect of variable weather (Rodríguez et al., 1990a; Hossain et al., 2003). The recommended practice is to stop grazing prior to the wheat reaching the jointing stage, specifically at the stage of first hollow stem (Redmon et al., 1996). The stage of first hollow stem is equivalent to 3.0 at the Zadoks' scale (Zadoks et al., 1974). Research has shown that light to moderate grazing of winter wheat before first hollow stem had little or no effect on wheat grain yield, but wheat grazing past first hollow stem reduced grain yield (Christiansen et al., 1989; Redmon et al., 1996; Fieser et al., 2004). These conclusions were based on comparisons between dual-purpose and grain-only systems that had the same planting dates (i.e., the grainonly wheat was planted when the dual-purpose wheat was planted). However, when grain-only wheat was planted later than dual-purpose wheat, there was a 10 to $40 \%$ decrease in grain yields from plots that were grazed or clipped before first hollow stem (Winter and Thompson, 1987; 1990; Winter and Musick, 1991; Ud-Din et al., 1993). Khalil et al. (2002) also reported a decrease in grain yield in the dual-purpose systems when grazing was terminated before first 
hollow stem. The decrease, averaged across 12 hard red winter wheat varieties, was $49 \%$ in 1997 (planted on 3 September for dual and 15 October for grain-only), 22\% in 1998 (3 September and 7 October), and close to zero in 1999 (28 September and 16 October), showing the effect of planting date, but planting date is confounded with weather variability. The large variation reported in grain yield reductions between the two systems might have resulted from differences in planting dates, grazing duration and intensity, and crop developmental stage when grazing ceased. In general, grazing the excess forage in early-planted winter wheat may have minimal effects on grain yield, if (i) soil moisture and fertility are adequate, (ii) grazing is terminated before the first hollow stem stage, and (iii) leaf regeneration potential is good following grazing termination (Redmon et al., 1995; Khalil et al., 2002).

Biophysically based crop models such as those found in DSSAT may be used to simulate the effects of defoliation and nutrient stress due to grazing on grain yield production. Those models can also be used to predict wheat growth stages so that cattle can be removed at a desirable date based on the maximum net return in the dual-purpose wheat systems. In addition, beef production per hectare is a function of average daily weight gain, stocking rate, and length of grazing period (Phillips and Albers, 1999). These management decisions can be readily optimized if a robust wheat grazing model is available to extension specialists and decision makers.

A simple wheat-grazing model was developed by combining the CERES-Wheat model (Ritchie and Otter, 1985) with empirical equations for animal intake and growth to simulate production of wheat and stocker cattle (Rodríguez et al., 1990a). This model was used to investigate economic risks associated with changes in stocking rates and duration of grazing when weather was a source of variation in the system (Rodríguez et al., 1990b). A number of improvements have been made in the CSM of DSSAT (version 4.02) in simulating soil water, nitrogen, carbon dynamics, and crop growth and development (Hoogenboom et al., 2003). Furthermore, new insights and understanding of wheat grazing, such as the quantitative impacts of grazing past first hollow stem on grain yield, have been reported (Winter and Thompson, 1987; Redmon et al., 1996; Fieser et al., 2004). It is logical and necessary to develop a wheat grazing model using the latest technology of the DSSAT model and improved understanding of wheat grazing to assist decision-making for better management of the wheat grain-cattle production enterprise. 
The objectives of this work are to develop a metabolizable energy-based cattle growth module and to incorporate it into the DSSAT model (v4.02) for simulating production of wheat grain and stocker cattle grazing on wheat during late fall and early spring for the U.S. Southern Great Plains. Evaluation and validation of the new model are critical to its acceptance and adoption by potential users and are presented in a companion paper in this issue (Zhang et al., 2008).

\section{DEVELOPMENT OF WHEAT GRAZING MODEL}

The wheat grazing model is comprised of three components: wheat growth and development, cattle-wheat interface, and cattle growth. Detailed description of each component as well as their key numerical relationships is presented below.

\section{Decision Support Systems for Agrotechnology Transfer Model and Its Wheat Module}

The DSSAT (v4.02) is a MS Windows-based, comprehensive decision support system for assessing crop management options (Tsuji et al., 1998; Gijsman et al., 2002; Hoogenboom et al., 2003). It includes a cropping system model (CSM) that simulates growth, development, and yield of a crop growing on a uniform land area under user-defined management and in changing biotic and abiotic environments over time (Jones et al., 2003). It encompasses more than 18 different crops and uses common weather, soil, and soil-plant-atmosphere modules to simulate soil water, nitrogen, and carbon balances for each crop (Hoogenboom et al., 2003; Jones et al., 2003).

Measured or generated daily weather data can be used by the model. The soil water balance module as described by Ritchie (1998) is similar to that developed for CERES-Wheat by Ritchie and Otter (1985). Water infiltration is modeled by the curve number method, deep drainage by a 'tipping bucket' approach, and upward unsaturated flow by empirical diffusion equations. The soil carbon and nitrogen balance module has two options: one based on Godwin and Jones (1991), and another derived from the CENTURY model (Parton et al., 1988), added for simulating carbon sequestration. The soil-plant-atmosphere module computes daily actual evapotranspiration (ET) using the Ritchie (1972) method. The potential ET is estimated by the methods of Priestley and Taylor (1972), Penman-FAO 24 (Doorenbos and Pruitt, 1977) or Penman-Monteith (Monteith, 1986). 
The wheat module in CSM (referred to as CSM-CERES-wheat) is a restructured and modified version of the original CERES-Wheat model of Ritchie and Otter (1985). It was modified to facilitate inclusion as a module in CSM, to externalize most variables, and to correct some problems that were discovered during the modification process (Hoogenboom et al., 2003). The CERES-Wheat model divides the wheat life cycle into several phases, and the duration of each phase is determined by genetic and environmental factors. For a given variety, phenological development is governed by thermal time or growing degree-days. The model focuses on three important aspects: growth rate, growth duration, and the extent to which environmental stresses influence these two processes (Ritchie and Otter, 1985; Ritchie et al., 1998). The model simulates a single wheat plant and uses morphological development to determine and track the appearance and number of leaves and tillers as well as number of grains on a daily basis. Daily plant growth is calculated by converting intercepted photosynthetically active radiation into plant dry matter (DM) using a radiation use efficiency parameter. Light interception is a function of leaf area index (LAI), which is computed from total plant leaf area. Potential daily growth is modified by water, nitrogen, and air temperature as limiting factors, and the resulting estimate of actual daily growth is partitioned to different plant organs according to phenological stages. Effects of diseases, pests, weeds, lodging, hail, and nutrients other than nitrogen are not modeled in the current CSM CERES-wheat module.

\section{Wheat-Cattle Interface}

A graze subroutine is called from the wheat growth model on each day of the grazing season, and canopy top weight or above ground biomass $\left(\mathrm{kg} \mathrm{ha}^{-1}\right)$ is passed to the graze subroutine. Total grazed DM (referred as GW in $\mathrm{kg} \mathrm{ha}^{-1}$ ) for that day is the estimated DM consumed by cattle plus $10 \%$ waste and returned to the wheat growth model for growth adjustment. Rate variables relevant to grazing removal are estimated at the beginning of each day on a daily basis, and the corresponding state variables are updated at the end of the day. The fraction (FR) of dry matter removal is used in all adjustments on a daily basis.

$$
\mathrm{FR}=\mathrm{GW} /(\mathrm{CW}+\mathrm{DW})
$$

where GW is the grazed top weight in $\mathrm{kg} \mathrm{ha}^{-1}, \mathrm{CW}$ is the canopy top weight in $\mathrm{kg} \mathrm{ha}^{-1}$, and DW is the dead leaf weight. Dead leaves or tillers are not included in CW before first hollow stem, and are included in Eq. [1] because cold temperature often kills top parts of leaves and tillers that 
are still grazed by cattle. Since wheat grazing takes place in early vegetative growth stages in the dual-purpose production systems, nonselective removal of wheat tops by cattle is assumed. Thus, leaf weight, stem weight if any, and reserve weight of nonstructural carbohydrates and proteins are reduced by the same fraction (i.e., the rates of removal per day are proportional to their contributions to total top dry matter) using Eq. [2a-c].

$$
\begin{aligned}
& \mathrm{LWG}=\mathrm{LW} \times \mathrm{FR} \\
& \mathrm{SWG}=\mathrm{SW} \times \mathrm{FR} \\
& \mathrm{RWG}=\mathrm{RW} \times \mathrm{FR}
\end{aligned}
$$

where LWG, SWG, and RWG are the grazed leaf, stem, and reserve weights, respectively, in $\mathrm{g} \mathrm{d}^{-}$ ${ }^{1}$ plant $^{-1}$; and LW, SW, and RW are the leaf, stem, and reserve weights in $\mathrm{g} \mathrm{plant}^{-1}$ on that day. In order not to alter nitrogen concentration in plant parts in nitrogen stress calculation, the rates of nitrogen removals in leaves, stems, and reserves are also adjusted proportionally to their dry matter adjustment on the same day using Eq. [3a-c].

$$
\begin{aligned}
& \mathrm{LNG}=\mathrm{LN} \times \mathrm{FR} \\
& \mathrm{SNG}=\mathrm{SN} \times \mathrm{FR} \\
& \mathrm{RNG}=\mathrm{RN} \times \mathrm{FR}
\end{aligned}
$$

where LNG, SNG, and RNG are the grazed leaf, stem, and reserve nitrogen weights, respectively, in $\mathrm{g} \mathrm{d}^{-1}$ plant $^{-1}$; and $\mathrm{LN}, \mathrm{SN}$, and $\mathrm{RN}$ are the leaf, stem, and reserve nitrogen weights in $g$ plant ${ }^{-1}$ on the day. To make sure that the specific leaf area (leaf area per unit mass) is not altered by cattle grazing, the total plant leaf area per plant $\left(\mathrm{cm}^{2}\right.$ plant $\left.{ }^{-1}\right)$ is also scaled down by the same fraction using Eq. [4].

$$
\mathrm{PLAG}=(\mathrm{PLA}-\mathrm{SENLA}) \times \mathrm{FR}
$$

where PLAG is the rate of plant leave area removed by grazing per day $\left(\mathrm{cm}^{2}\right.$ plant $\left.^{-1} \mathrm{~d}^{-1}\right)$, PLA is the cumulative total plant leaf area $\left(\mathrm{cm}^{2}\right.$ plant $\left.{ }^{-1}\right)$ on the day, and SENLA is the senesced cumulative leaf area $\left(\mathrm{cm}^{2}\right.$ plant $\left.{ }^{-1}\right)$ on the day.

At the end of each grazing day, relevant state variables are updated for grazing using the rate variables presented above using Eq. [5]. 


$$
\mathrm{LW}_{\mathrm{t}}=\mathrm{LW}_{\mathrm{t}-1}-\mathrm{LWG}
$$

where $\mathrm{LW}_{\mathrm{t}}$ and $\mathrm{LW}_{\mathrm{t}-1}$ are the leaf weights of today and yesterday in $\mathrm{g}$ plant ${ }^{-1}$, respectively. Likewise, SW, RW, LN, SN, and RN are updated. The cumulative senesced leaf area of today $\left(\mathrm{SENLA}_{\mathrm{t}}\right)$ is updated using Eq. [6]:

$$
\text { SENLA }_{t}=\text { SENLA }_{\mathrm{t}-1}+\text { PLAG }
$$

where SENLA $\mathrm{t}_{\mathrm{t}-1}$ is the cumulative senesced leaf area of yesterday. The grazed plant leaf area (PLAG) is uniformly distributed among all live leaves, assuming nonselective grazing. Specifically, individual live leaves regardless of their positions or ages are reduced by the same fraction of FR, and the reduced leaf areas are added to their corresponding senesced leaf areas. Grazed leaves are added to the senesced leaves to complete carbon and nitrogen cycling because nutrient cycling through the return of animal manure and urine is not directly simulated in the current model.

Preferable grazing of young leaves rather than uniform grazing of leaves of all ages is not simulated. This approach was tried, but found to lead to wheat failure under intensive grazing because total leaf area was often reduced to zero, as older leaves senesce and young leaves are grazed.

Finally, the effect of cattle grazing on grain yield is considered. As reviewed earlier, several studies showed that light to moderate grazing of winter wheat before first hollow stem had little effect on wheat grain yield (Redmon et al., 1996). However, a preliminary simulation evaluation showed a $5-20 \%$ reduction in grain yield following fall and winter grazing at a stocking rate of 1 head ha $^{-1}$ (data not presented). In the CSM model, the number of grains per plant (GRP), which determines the potential grain yield, is set as shown in Eq. [7]:

$$
\mathrm{GRP}=(\mathrm{LW}+\mathrm{SW}+\mathrm{RW}) \times \mathrm{C} 1
$$

where $\mathrm{C} 1$ as an input crop coefficient is defined as grain numbers per unit canopy weight at anthesis. If SW is only used in Eq. [7], the yield loss due to grazing is reduced, on average, by $50 \%$. But grain yield becomes more variable from year to year. If SW and RW are used, similar grain yields to Eq. [7] are obtained because LW is only a small fraction of the canopy weight at anthesis. Owing to lack of satisfactory solution, no modification has been made to grain number setting in this version. However, Eq. [7] may be modified in future when better understanding of grazing on yield dynamics becomes available. 
Several field studies have shown that cattle grazing past first hollow stem resulted in considerable additional loss of grain yield due to loss of spikes by grazing and trampling. Redmon et al. (1996) reported that grain yield decreased $83 \mathrm{~kg} \mathrm{ha}^{-1} \mathrm{~d}^{-1}$ (3.8\% per day) as cattle grazed past first hollow stem. Fieser et al. (2004) showed that wheat grain yield decreased about $34 \mathrm{~kg} \mathrm{ha}^{-1} \mathrm{~d}^{-1}(1.3 \%)$ for each day of grazing past first hollow stem based on a grazing experiment during the 2002-2003 winter wheat season. Winter and Thompson (1987) reported grain loss of $50-85 \mathrm{~kg} \mathrm{ha}^{-1} \mathrm{~d}^{-1}(1.3-2.1 \%)$ for each day of grazing past first hollow stem in a three-year wheatgrazing study under irrigated conditions. These studies showed that the rate of grain yield reduction per day was more or less constant and somewhat independent of the stocking rates and was likely to be within the range of $34-85 \mathrm{~kg} \mathrm{ha}^{-1} \mathrm{~d}^{-1}$. To accommodate these aspects, grain yield and relevant variable changes due to loss of spikes are adjusted at harvest using Eqs. [8a-d]:

$$
\begin{aligned}
& \mathrm{YG}=\mathrm{C} 3 \times \mathrm{N}_{\mathrm{d}} \\
& \mathrm{GRA}_{\mathrm{t}+1}=\mathrm{GRA}_{\mathrm{t}} \times\left(1-\mathrm{YG} / \mathrm{Y}_{\mathrm{t}}\right) \\
& \mathrm{EAR}_{\mathrm{t}+1}=\mathrm{EAR}_{\mathrm{t}} \times\left(1-\mathrm{YG} / \mathrm{Y}_{\mathrm{t}}\right) \\
& \mathrm{Y}_{\mathrm{t}+1}=\mathrm{Y}_{\mathrm{t}}-\mathrm{YG}
\end{aligned}
$$

where $\mathrm{YG}$ is the yield reduction due to grazing in $\mathrm{kg} \mathrm{ha}^{-1}$; $\mathrm{C} 3$ is a rate constant of yield reduction in $\mathrm{kg} \mathrm{d}^{-1} \mathrm{ha}^{-1} ; \mathrm{N}_{\mathrm{d}}$ is the number of days grazing past first hollow stem in $\mathrm{d} ; \mathrm{GRA}_{\mathrm{t}}$ and $\mathrm{GRA}_{\mathrm{t+1}}$ are the grain numbers per hectare before and after adjustment, respectively; $Y_{t}$ and $Y_{t+1}$ are grain yields before and after adjustment in $\mathrm{kg} \mathrm{ha}^{-1}$; and $\mathrm{EAR}_{\mathrm{t}}$ and $\mathrm{EAR}_{\mathrm{t}+1}$ are the numbers of ears per hectare before and after adjustment. The above adjustment is based on the assumption that only the spikes are removed and the rest of tillers are left intact. Theoretically, C3 should be positively related to stocking rates but inversely related to canopy top weight during grazing. In addition, growing conditions after grazing ceases may affect C3. Favorable conditions can lessen yield loss by altering seed weights and tiller mortality rates. Unfortunately, there are not enough experimental data to quantify these relationships, and an arbitrary value of $50 \mathrm{~kg} \mathrm{ha}^{-1} \mathrm{~d}^{-1}$ is used in the model for the time being. The trivial adjustment on grain numbers and ear numbers is to ensure that the simulated grain numbers per ear is not affected by grazing past first hollow stem in the model output. Note that it is affected by grazing before first hollow stem, see Eq. [7]. 
Redmon et al. (1996) emphasized that grazing could delay early phenological development, and grazing termination should base on the first hollow stem stage of ungrazed wheat. The delaying effect of grazing on phenological development is not simulated in the model. Wheat biomass removal by grazing, as modeled here, alters only morphologic development but not physiological and phenological development. Thus, the first hollow stem stage predicted in the model will be the same with or without grazing, which is consistent with the recommendation of Redmon et al. (1996). As a matter of fact, the delay of wheat phenological development due to grazing is largely unknown and needs to be quantified in order to be incorporated into grazing models for better grain yield prediction.

\section{Cattle Growth}

Forage quality and live animal weight $(L W T, \mathrm{~kg}$ ) are used to calculate maximum voluntary intake $\left(M V I, \mathrm{~kg} \mathrm{~d}^{-1}\right.$ steer $\left.^{-1}\right)$ for growing and finishing cattle based on the recommended method of the National Research Council (NRC, 1984) using Eq. [9]:

$$
M V I=L W T^{0.75}\left(0.1493 N E_{m}-0.046 N E_{m}^{2}-0.0196\right)
$$

where $N E_{m}$ is the net energy available in feedstuffs (forage quality) for animal maintenance (Mcal kg${ }^{-1}$ ). The calculated $M V I$ increases for increasing $N E_{m}$ up to $1.62 \mathrm{Mcal} \mathrm{kg}^{-1}$. For steers with body weight (BW) less than $360 \mathrm{~kg}$, the $M V I$ is not allowed to exceed $10 \%$ of the metabolic BW (metabolic BW $=L W T^{0.75}$ ) (Rodriguez et al., 1990a). Net energy in feedstuffs for maintenance $\left(N E_{m}\right)$ and for animal weight gain $\left(N E_{g}\right.$, Mcal kg-1 $)$ are estimated using Eqs. $[9,10]$ (NRC, 1984):

$$
\begin{aligned}
& N E_{m}=1.37 M E-0.138 M E^{2}+0.0105 M E^{3}-1.12 \\
& N E_{g}=1.42 M E-0.174 M E^{2}+0.0122 M E^{3}-1.65
\end{aligned}
$$

where $M E\left(\mathrm{Mcal} \mathrm{kg}^{-1}\right)$ is the metabolizable energy in feedstuff and equals to 0.85 times digestible energy in the feedstuff ( $\left.D E, \mathrm{Mcal} \mathrm{kg}^{-1}\right)$. The digestible energy is internally set to a typical value of $3.22 \mathrm{Mcal} \mathrm{kg}^{-1}$ for fresh early vegetative wheat is according to NRC (1984).

The maximum voluntary intake calculated by Eq. [9] needs to be adjusted for forage availability, temperature, and acclimation requisite (adaptation to new forage). The forage availability adjustment $(F A A)$ is set to 1 when the canopy top weight $\left(C W T, \mathrm{~kg} \mathrm{ha}^{-1}\right)$ is greater 
than $1300 \mathrm{~kg} \mathrm{ha}^{-1}$ (a default threshold for high biomass level, $C W T_{h}$ ), reflecting that there is no forage limitation for cattle intake above this value. When $C W T$ is less than $500 \mathrm{~kg} \mathrm{ha}^{-1}$ (another default threshold for low biomass level, $\left.C W T_{l}\right), F A A$ is estimated using Eq. [12a]:

$$
F A A=\frac{0.012 \times L W T}{M V I}
$$

Equation [12a] assumes that when $C W T$ is below $C W T_{l}$, the grazing steer is in the survival mode and consumes wheat forage only at the maintenance level of $1.2 \%$ of the body weight (i.e., at about $50 \%$ of its maximum intake). When $C W T$ is between the two thresholds, $F A A$ is calculated via a linear interpolation as:

$$
F A A=1-\left(1-\frac{0.012 \times L W T}{M V I}\right)\left(\frac{C W T_{h}-C W T}{C W T_{h}-C W T_{l}}\right)
$$

The adjustment factor from Eq. [12b] varies from a minimum of about 0.5 from Eq. [12a] to 1. The default values for $C W T_{h}$ and $C W T_{l}$ are based on experimental data collected at El Reno and elsewhere in Oklahoma. However, users can input their own values if specific measurements are available.

Voluntary intake can be affected by ambient air temperature outside the thermoneutral zone of 15 to $25{ }^{\circ} \mathrm{C}$ (NRC, 1984). High temperature stress suppresses intake, while low temperature increases intake to compensate for increased demand of the maintenance energy in cold weather. For simulating winter grazing, only low temperature adjustment is considered in the model. Voluntary intake is increased by $0.25 \%$ for each degree decrease in daily mean air temperature between 15 and $-5{ }^{\circ} \mathrm{C}$, and increased by $0.5 \%$ for each degree decrease between -5 and $-15^{\circ} \mathrm{C}(\mathrm{NRC}, 1987)$. The factor of air temperature adjustment (TA) ranges between 1.1 and 1 for any temperature between -15 and $15^{\circ} \mathrm{C}$.

Many grazing experiments showed that average daily weight gain is near zero during the first week after cattle are introduced to wheat pasture, and gradually increases to a normal level of weight gain within the next week (Phillips et al., 2006). The reduction in weight gain is an integrated result of metabolic and physiological adaptation of cattle to a new type of forage. An arc tangent function used by Rodriguez et al. (1990a) was applied to simulate adaptation adjustment $(A A)$ during the first 14 days on wheat pasture. The function was calibrated to an 
overall trend generalized from experimental data and observations made in El Reno (Vogel, 1985; Phillips and Albers, 1999) using Eq. [13]:

$$
A A=0.80+0.16 \times \arctan [0.15 \pi(N-10)]
$$

where $N$ is the number of days on wheat, ranging from 1 to 14. The $A A$ factor from Eq. [13] ranges from about 0.6 during the first 7 days to near 1 at the $14^{\text {th }}$ day. The inflection point of the function is at $A A=0.8$ and $N=10$. That is, forage intake reaches $80 \%$ of the normal voluntary intake rate at the $10^{\text {th }}$ day.

Actual forage intake ( $\left.A V I, \mathrm{~kg} \mathrm{~d}^{-1} \mathrm{steer}^{-1}\right)$ is calculated using Eq. [14]:

$$
A V I=M V I \times F A A \times T A \times A A
$$

During the 14-day adaptation period, only the smaller of the forage availability adjustment $(F A A)$ and the adaptation adjustment $(A A)$ is used in Eq. [14] to avoid double counting because both adjustments have the potential to reduce forage intake to the maintenance level.

Live weight gain $\left(L W G, \mathrm{~kg} \mathrm{~d}^{-1}\right)$ for a medium-frame steer is calculated using Eq. [15] (NRC, 1984):

$$
L W G=13.91 N E_{a g}^{0.9116} \times L W T^{-0.6837}
$$

where $N E_{a g}\left(\mathrm{Mcal} \mathrm{d}^{-1}\right)$ is the net energy available to the animal for weight gain, and may be estimated by using Eq. [16] (Rodriguez et al., 1990a):

$$
N E_{a g}=\left(A V I-\frac{N E_{r m}}{N E_{m}}\right) \times N E_{g}
$$

where $N E_{r m}\left(\mathrm{Mcal} \mathrm{d}^{-1}\right)$ is the net energy required by the animal for maintenance, and is calculated using Eq. [17]:

$$
N E_{r m}=[0.077+0.0007(15-T e m p)] \times L W T^{0.75}
$$

where Temp is the daily mean air temperature in ${ }^{\circ} \mathrm{C}$. Equation [17] accounts for a $1 \%$ increase in maintenance requirement per degree decrease below $15^{\circ} \mathrm{C}$.

Equation [16] is used when $N E_{a g}$ is positive, i.e., there is a net weight gain. Otherwise, $N E_{m}$ is used in the place of $N E_{g}$ to compute $N E_{a g}$ in Eq. [16]. A negative value of $N E_{a g}$ means that maintenance requirement is not met and body tissue has to be catabolized to offset the 
energy deficit. If an energy content of $5 \mathrm{Mcal}$ per kg body weight is assumed (Rodriguez et al., 1990a), weight loss in $\mathrm{kg} \mathrm{d}^{-1}$ is calculated by dividing $N E_{\text {ag }}$ by $5\left(\mathrm{Mcal} \mathrm{kg}^{-1}\right)$.

\section{MODEL INPUT AND OUTPUT}

The grazing subroutine is automatically called and executed each day during winter grazing when a graze input file is detected in the Graze subdirectory. Otherwise, the original DSSAT wheat model is executed. The grazing can be managed in two modes: automatic grazing or fixed date grazing. In the automatic mode, grazing is initiated once the canopy top weight $\left(C W T, \mathrm{~kg} \mathrm{ha}^{-1}\right)$ reaches the user-defined threshold for initiation of grazing. Grazing is terminated when $C W T$ hits the user-defined level for termination of grazing, or when wheat reaches the stage of first hollow stem (FHS) to minimize grain loss. In the fixed mode, grazing is turned on and off according to the user-specified dates, except that grazing is terminated when the canopy top weight hits the pre-set minimum critical biomass to avoid crop failure. In the fixed mode, grazing is allowed to continue after FHS, and the number of days past FHS is saved for making additional adjustment to grain yield as presented earlier.

\section{Input Requirement}

Information on daily weather, soil, crop coefficients, and crop management is required to run the DSSAT model (Jones et al., 2003; Hoogenboom et al., 2003). Weather data include measured or internally generated daily precipitation amounts, maximum and minimum air temperatures, and solar radiation. Soil data include general physical and chemical properties by soil layers, initial soil moisture and nutrient conditions, and SCS-Curve Number for the soil. Five crop coefficients, determined by wheat genotype are used, and these need to be calibrated to the particular variety and perhaps also, location of interest. Crop management includes tillage operations, fertilizer and irrigation management, chemical applications, planting and harvest details such as date, population, and geometry. On top of the general requirements for running the CSM CERES-wheat of DSSAT, the following inputs are required by the wheat grazing subroutine: starting and terminating dates for fixed date grazing, canopy top weight for initiating and terminating grazing for automatic grazing, initial stocker body weight, stocking rate, and optional high and low top biomass thresholds that are used for forage availability adjustment. 


\section{Model Output}

The DSSAT outputs provide an overview of input data, overall crop performance, as well as detailed simulation results including daily growth and development, water balance, nitrogen balance, and carbon balance (Tsuji et al., 1998; Hoogenboom et al., 2003). The wheat grazing subroutine generates two additional output files. One includes starting and ending dates of grazing and final stocker weight for each year of simulation. Another provides daily data including stocker body weight, grazed dry biomass, and canopy top weight. The summary and daily data can be imported to spreadsheets and analyzed with an economic model for simple cost-benefit analysis. At this stage, the built-in economic analysis tools in DSSAT version 4.02 are not linked to cattle data, and therefore cannot be used to analyze economic return for the wheat grain-cattle production enterprise. 


\section{REFERENCES}

Christiansen, S., T. Svejcar, and W.A. Phillips. 1989. Spring and fall cattle grazing effects on components and total grain yield of winter wheat. Agron. J. 81:145-150.

Doorenbos, J., and W.D. Pruitt. 1977. Guidelines for predicting crop water requirements. Irrigation and drainage paper No. 24. The United Nations-FAO, Rome, Italy.

Fieser, B.G., G.W. Horn, E.G. Krenzer, and S.A. Schaefer. 2004. Effect of time of grazing termination of winter wheat pasture on cattle performance and subsequent grain yield. Publication P-1008. Oklahoma State Univ., Agric. Exp. Stn., Stillwater, OK.

Gijsman, A.J., G. Hoogenboom, W.J. Parton, and P.C. Kerridge. 2002. Modifying DSSAT crop models for low-input agricultural systems using a soil organic matter-residue module from CENTURY. Agron. J. 94:462-474.

Godwin, D.C., and C.A. Jones. 1991. Nitrogen dynamics in soil-plant systems. p. 287-321. In J. Hanks and J.T. Ritchie (ed.) Modeling plant and soil systems. ASA, CSSA, and SSSA, Madison, WI.

Hoogenboom, G., J.W. Jones, C.H. Porter, P.W. Wilkens, K.J. Boote, W.D. Batchelor, L.A. Hunt, and G.Y. Tsuji. 2003. DSSAT Version 4.0, Volume 1: Overview, Univ. of Hawaii, Honolulu, HI.

Hossain, I., F.M. Epplin, and E.G. Krenzer, Jr. 2003. Planting date influence on dual-purpose winter wheat forage yield, grain yield, and test weight. Agron. J. 95:1179-1188.

Hossain, I., F.M. Epplin, G.W. Horn, E.G. Krenzer, Jr. 2004. Wheat production and management practices used by Oklahoma grain and livestock producers. Bull. 818 . Oklahoma State Univ., Agric. Exp. Stn., Stillwater, OK.

Jones, J.W., G. Hoogenboom, C.H. Porter, K.J. Boote, W.D. Batchelor, L.A. Hunt, P.W. Wilkens, U. Singh, A.J. Gijsman, and J.T. Ritchie. 2003. The DSSAT cropping system model. Europ. J. Agron. 18:235-265.

Khalil, I.H., B.F. Carver, E.G. Krenzer, C.T. MacKown, and G.W. Horn. 2002. Generic trends in winter wheat yield and test weight under dual-purpose and grain-only management systems. Crop Sci. 42:710-715.

Monteith, J.L. 1986. How do crops manipulate water supply and demand? Philos. Trans. R. Soc. London, Ser. A 316:245-259.

NRC (National Research Council). 1984. Nutrient Requirements of Beef Cattle. Natl. Academy Press, Washington, D.C.

NRC (National Research Council). 1987. Predicting feed intake of food-producing animals. Natl. Academy Press, Washington, D.C.

Parton, W.J., J.W.B. Stewart, and C.V. Cole. 1988. Dynamics of C, N, P and S in grassland soils: a model. Biogeochemistry 5:109-131.

Phillips, W.A. and R. Albers, 1999. The effect of herbicide application during the winter on forage production, animal performance, and graion yield of winter wheat. Prof. Anim. Sci. 15:141-147.

Phillips, W.A., S. W. Coleman, and H.S. Mayeux. 2006. Case Study: Changes in body weight, fill, and shrink of calves grazing wheat pasture in the winter and spring. Prof. Anim. Sci. 22:267-272.

Priestley, C.H.B., and R.J. Taylor. 1972. On the assessment of surface heat flux and evaporation using large scale parameters. Monthly Weather Rev. 100:81-92. 
Redmon, L.A., G.W. Horn, E.G. Krenzer, Jr., and D.J. Bernardo. 1995. A review of livestock grazing and wheat grain yield: Boom or Bust? Agron. J. 87:137-147.

Redmon, L.A., E.G. Krenzer, Jr., D.J. Bernardo, and G.W. Horn. 1996. Effect of wheat morphological stage at grazing termination on economic return. Agron. J. 88:94-97.

Ritchie, J.T. 1972. Model for predicting evaporation from a row crop with incomplete cover. Water Resour. Res. 8:1204-1213.

Ritchie, J.T. 1998. Soil water balance in plant water stress. p. 41-54. In G.Y. Tsuji, G. Hoogenboom, and P.K. Thornton (ed.) Understanding options for agricultural production. Kluwer Academic Publ., Dordrecht, The Netherlands.

Ritchie, J.T., and S. Otter. 1985. Description and performance of CERES-Wheat: a user-oriented wheat yield model. p. 159-175. In ARS Wheat Yield Project. ARS-38. Natl. Tech. Info. Serv., Springfield, VA.

Ritchie, J.T., U. Singh, D.C. Godwin, W.T. Bowen. 1998. Cereal growth, development and yield. p. 79-98. In G.Y. Tsuji, G. Hoogenboom, and P.K. Thornton (ed.) Understanding options for agricultural production. Kluwer Academic Publ., Dordrecht, The Netherlands.

Rodríguez, A., J.N. Trapp, O.L. Walker, and D.J. Bernardo. 1990a. A wheat grazing systems model for the US Southern Plains: Part I- Model description and performance. Agric. Syst. $33: 41-59$.

Rodríguez, A., J.N. Trapp, O.L. Walker, and D.J. Bernardo. 1990b. A wheat grazing systems model for the US Southern Plains: Part II- Economic analysis of grazing management decisions under weather uncertainty. Agric. Syst. 33:61-75.

Tsuji, G.Y., G. Hoogenboom, and P.K. Thornton (ed.) 1998. Understanding options for agricultural production. Kluwer Academic Publ., Dordrecht, The Netherlands.

Ud-Din, N., B.F. Carver, and E.G. Krenzer, Jr. 1993. Visual selection for forage yield in winter wheat. Crop Sci. 33:41-45.

Vogel, G.J. 1985. Influence of supplemental silage on forage intake and utilization and performance of stocker cattle grazing wheat pasture and bermudagrass. MS Thesis. Oklahoma State Univ., Stillwater, OK.

Winter, S.R., and J.T. Musick. 1991. Grazed wheat grain yield relationships. Agron. J. 83:130135.

Winter, S.R., and E.K. Thompson. 1987. Grazing duration effects on wheat growth and grain yield. Agron. J. 79:110-114.

Winter, S.R., and E.K. Thompson. 1990. Grazing winter wheat: I. Response of semidwarf cultivars to grain and grazed production systems. Agron. J. 82:33-37.

Zadoks, J.C., T.T. Chang, and C.F. Konzak. 1974. A decimal code for the growth stages of cereals. Weed Res. 14:415-421.

Zhang, X.C., L.A. Hunt, W.A. Phillips, G.W. Horn, J. Edwards, and H.L. Zhang. 2008. A wheat grazing model for simulating grain and beef production: Part II-model validation. Agron. J. (this issue) 